\title{
Occupational Safety and Health amid the Global Pandemic
}

Occupational Safety and Health (OSH) is a field in public health that aims to achieve the highest level of health and well-being in all types of work, employment, and occupations through the promotion and prevention of work-related injuries, diseases, and disabilities. OSH is key to increasing the working capacity, productivity, and satisfaction of workers. Workers comprise nearly half of the world's population with an estimated number of 3.5 billion. ${ }^{1}$ However, more than 2 million workrelated fatalities are reported annually. ${ }^{2}$ Likewise, an average of 360 million accidents occur in the workplace and 160 million suffer from work-related illnesses every year. ${ }^{2}$ Initiatives towards health in the workplace can reduce absenteeism by $27 \%$ and healthcare costs for companies by $26 \%$.

The burden of work-related health problems is evident. Long hours of work attributing to at least 750,000 deaths is found to increase fatalities from heart diseases by $41 \%$ and stroke by $19 \%$. Work exposures to air pollution, asthmagens, carcinogens, ergonomic, and other risk factors are linked to 450,000 fatalities. An estimated 360 million non-fatal accidents occur annually leading to loss of productivity and at least four days of absence from work. ${ }^{3}$ In the Philippines, 17 out of 18 workers or 38.8 million workers are exposed to unsafe working conditions. ${ }^{4}$ Although a majority of countries have come up with institutional arrangements and strategies for $\mathrm{OSH}$, the global survey on occupational health services shows low coverage of OSH. Around $70 \%$ of the total labor force in the world has limited infrastructure, institutional and human resources, which serve as the major hindrance in implementing OSH. ${ }^{5}$ In the Philippines, during the COVID-19 pandemic, the OSH law was strengthened to increase the awareness of workers of their rights that their safety and health at work are guaranteed, to refuse work that posed an imminent danger, to report accidents, and to mandate the use of personal protective equipment (PPEs) and other safety devices. ${ }^{6}$

During the COVID-19 pandemic, occupational health and safety activities played a critical role in a safe and healthy workplace. COVID-19 prevention practices such as the use of sanitizers, social distancing, new work shifts, and disinfection of workplaces as forms of risk management and biological risk mitigation were linked to improved safety and health performance. ${ }^{7}$ However, the 'work from home' as the 'new normal form of work arrangement' has posed health challenges. The most prevalent physical health problems for working from home were body weight gain at a rate of $40.97 \%$, ergonomic problems that lead to musculoskeletal problems, psychosocial issues, indoor environmental pollution, and lifestyle changes in eating patterns, sleeping habits, and exercise. ${ }^{8}$

Amid the protracted pandemic, the role of OSH is indeed critical and has changed its focus from the traditional workplace to bringing and doing work at home, as well as emphasizing the link between environmental health and occupational health. Environmental toxins and viruses are among the biological hazards that can be brought from the environment and the community to the workplace, and vice-versa. It is imperative to rethink the framework and strategies of OSH to that from being mainly work-related to a continuum of workplace-environment context; programs and policies should target both these areas. A good example of showing the work-environmental health link is when it comes to inhaling dangerous chemicals at work. It has been shown that while the respiratory system is the primary target organ of SARS-CoV-2, exposure to chemicals in the workplace such as formaldehyde and ammonium compounds, raises the risk of respiratory symptoms and clinical indications among those with SARS-CoV-2 infection. ${ }^{9}$ Higher levels of air pollution were associated with a higher incidence and mortality rates from COVID-19. ${ }^{9}$ 
On a global dimension, the spread and/ or prevention of the spread of SARS-CoV-2 is closely related to water and sanitation. A key recommendation is regular washing of hands for health and hygiene; however, a significant number of the global population currently lacks access to water and sanitation. Corollary to this, wastewater also plays a role in the spread of the virus within communities (KWR, 2020 as cited by OECD, 2021). ${ }^{10}$ Hence, OSH has both macro- and micro-level implications and is tied to global resources such as water.

Amid the COVID-19 pandemic, a global health challenge in the twenty-first century is coming to the fore - that which is in dire need of a comprehensive OSH policy covering both traditional workplace and home workplace. There is a need for a paradigm shift from a siloed OSH as a stand-alone policy to one that encompasses the wider environment and communityat-large, both locally and cross-border. Institutional and social responsibility efforts to build an intersectoral, whole-of-society, and whole-of-the globe approach are necessary to promote healthier and safer work environments. The call for access to global resources such as water makes OSH a geopolitical concern as well. In all of this, people-centered and universal health coverage for a dedicated policy and programs for OSH especially with the COVID-19 pandemic will make the world of work safer and healthy.

\author{
Jinky Leilanie Lu, MOH, PhD \\ National Institutes of Health \\ University of the Philippines Manila \\ University Scientist III - UP System \\ Secretary - International Commission of Occupational Health - \\ Mining Occupational Safety and Health (ICOH-MinOSH)
}

\title{
REFERENCES
}

1. World Health Organization (WHO). Protecting worker's health [Internet]. 2017 [cited 2022 Jan]. Available from: https://www.who.int/en/newsroom/fact-sheets/detail/protecting-workers'-health

2. International Labour Organization (ILO). Safety and health at work [Internet]. 2021. [cited 2022 Jan]. Available from: https://www.ilo.org/global/ topics/safety-and-health-at-work/lang--en/index.htm

3. World Health Organization - International Labour Organization (WHO/ILO). WHO/ILO joint estimates of the work-related burden of disease and injury, 2000-2016: global monitoring report [Internet]. 2021 [cited 2022 Jan]. Available from: https://www.who.int/publications/i/ item/9789240034945.

4. International Labour Organization Country Office for the Philippines (CO-Manila). Safety and health at work in the Philippines [Internet]. N.d. [cited 2022 Jan]. Available from: https://www.ilo.org/manila/areasofwork/safety-and-health-at-work/lang--en/index.htm

5. Rantanen J, Lehtinen S, Valenti A, Iavicoli S. A global survey on occupational health services in selected international commission on occupational health (ICOH) member countries. BMC Public Health. 2017; 17(1):787.

6. Film Development Council of the Philippines (FDCP). OSH Law (RA 11058) [Internet]. N.d. [cited 2022 Jan]. Available from: https://safefilming. ph/osh-law-ra11058

7. de Oliveira Neto GCO, Tucci HNP, Filho MG, Lucat WC, Correia JMF. Performance evaluation of occupational health and safety in relation to the COVID-19 fighting practices established by WHO: survey in multinational industries. Saf Sci. 2021; 141(2021):105331.

8. Ekpanyaskul C, Padungtod C. Occupational health problem and lifestyle changes among novice working-from-home workers amid the COVID-19 pandemic. Saf Health. 2021; 12(2021):384-9.

9. Sly P, Trottier B, Bulka C, Cormier S, Fobil J, Fry R, et al. The interplay between environmental exposure and COVID-19 risks in the health of children. Environ Health. 2021; 20(34):1-10.

10. Organisation for Economic Co-Operation and Development (OECD). Environmental health and strengthening resilience to pandemics [Internet]. 2021 Apr 21. [cited 2022 Jan]. Available from: https://www.oecd.org/coronavirus/policy-responses/environmental-health-and-strengtheningresilience-to-pandemics-73784e04/ 